\title{
The Inductiveness of Agricultural Village-Type Cluster Creation in Developing Countries
}

\author{
Lyudmila Ivanovna Petrova', Nadezda Yurievna Glubokova², \\ Ravil Gabdullaevich Akhmadeev ${ }^{3 *}$, Olga Alekseevna Bykanova ${ }^{4}$, \\ Elena Igorevna Artemova ${ }^{5}$, Ramzil Borisovich Gabdulkhakov ${ }^{6}$ \\ 'Altai State University, Russian Federation \\ 2,3,4Plekhanov Russian University of Economics, Russian Federation \\ ${ }^{5}$ Kuban State Agrarian University, Russian Federation \\ ${ }^{6}$ Ufa State Petroleum Technological University, Russian Federation \\ E-mail: 'lip@gmail.com, ${ }^{2}$ nyg@gmail.com, 3ahm_rav@mail.ru, ${ }^{4}$ oab@gmail.com, \\ ${ }^{5}$ eia@gmail.com, 6 rbg@gmail.com \\ ${ }^{*}$ Corresponding Author
}

\section{JEL Classification:}

F63

$\mathrm{O} 13$

Q18

Received: 06 June 2021

Revised: 15 July 2021

Accepted: 14 August 2021

\begin{abstract}
The assessment of emerging risks is substantial risk in implementing and creating various types of clusters used in the agricultural sector of the economy. In this regard, the goal is to develop practical measures to ensure the creation of a cluster of an agricultural settlement at the regional level, taking into account various types of risk that directly affect its creation and development. The study revealed that within the framework of the policy of substitution for domestic production and marketing of agricultural products during the formation of a cluster, it would allow combining more into a standard established system from production, processing to the sale of finished agricultural products both at the local level and at the federal level. This approach will significantly harmonize the interests of all participants of the agroindustry, as well as significantly simplify and expand access to external export markets, thereby reducing the cost of marketing research. At the same time, clustering will increase the overall economic impact on individual farmers, which will have a more significant impact on the development of non-resource zonal territories employed to produce agricultural products. Therefore, it will affect the increase in jobs in small villages.
\end{abstract}

\section{Keywords:}

Agro-Industrial Complex, Clusters, Agricultural Products, Exports, Economies

\section{How to Cite:}

Petrova, L. I., Glubokova, N. Y., Akhmadeev, R. G., Bykanova, O. A., Artemova, E. I., \& Gabdulkhakov, R. B. (2021). The Inductiveness of Agricultural Village-Type Cluster Creation in Developing Countries. Etikonomi, 20(2), 297 - 308. https://doi.org/10.15408/etk.v20i2.22014. 


\section{Introduction}

In order to influence the country's agri-food security, especially in the current conditions caused by the impact of COVID on the economies of most states, a study of policy of import substitution and gradual transition to the development of domestic products is of high importance. At the same time, an important aspect is the state policy supporting domestic agricultural producers in terms of competitiveness concerning imported ones and state subsidies. It should be noted that subsidies, preferential customs procedures, prices, and loans provided to both the most prominent companies and small businesses can be used as effective instruments of state support for agricultural producers. In this regard, the levers of state support are significant from the standpoint of macroeconomic policy, and the assessment of their effectiveness may largely depend on the degree of government intervention in the economy. In particular, economic researchers using the example of the impact of macroeconomic aspects in 2020 due to Brexit and Covid highlighted the activity of manufacturers as capable of supporting the supply of food products at an appropriate level, and at the same time, market constraints due to inequality of final buyers on the part of the state politics (Sanderson et al., 2021).

In turn, the policy of protectionism pursued by individual states, including in the agricultural sector, according to Caselli et al. (2021), mainly pursues political interests, taking into account the integration of the current WTO rules into the sphere of the plane of a particular jurisdiction. On the other hand, the introduction of unilateral tariff restrictions allows one to provide support both from agricultural products designed for mass consumption and the introduction of $4 \mathrm{G}$ technologies (Brisbois et al., 2019), which allows influencing the value of the costs of a trading company in the direction of their reduction (Ahmed et al., 2016). In turn, the construction of various models that can represent the dependence of the state's trade policy on the influence of various restrictions, we are talking about an increase in export duty rates or a decrease in tariffs on imported agricultural products, according to Bouët \& Debucquet (2012), is more capable of influencing an increase in world prices for agricultural products (Magdouli et al., 2016). This circumstance will directly affect countries' economies for which import consumption is the only way to provide their citizens with products. In this regard, customs and tariff methods and the fiscal policy pursued by the state rely to a greater extent on those food market participants who are capable of not leading to a price break in chains from the producer to the final buyer, as well as a violation of competitiveness for all entities (Warr, 2001; Du \& Li, 2020). In this regard, the emerging economic risks in the development of the agricultural sector of the economy can directly affect the distribution of labor and material resources.

Thus, the nature of understanding the sustainability of the goal based on an adequate perception of systemic relationships about the production and sale of agricultural products should first provide for the principle of interconnection. In practical terms, identifying various risks in the agricultural economy, such as under the influence of unfavorable natural conditions, climate change, obsolescence, and wear and tear of equipment, all directly affect the nature of investment activity (Brunori et al., 2020). At the same time, the nature of the seasonal influence, due to natural locations, directly affects the level of 
provision of a particular state with agricultural resources (Bacaria et al., 2015; Rahman \& Shavier 2018; Poghosyan, 2018).

When designing models for the functioning of comparative advantages about agricultural producers, an important place should be given, according to Baldos \& Hertel (2015), to the practical results obtained, taking into account the characteristics of the climate, in order to characterize the optimistic and pessimistic results of rational distribution for further research of the global trading system in terms of ensuring improved long-term food security up to 2050 (Antimanon et al., 2018). Various economists propose these features as a scientific and practical solution. In terms of integration into a single model, as a rule, they include various quantitative estimates that allow achieving a systemic relationship between the quality and the number of activities carried out (Zheng, 2016). When studying the value of creating clusters in the agricultural sector of the economy, potential advantages and limitations of their development are also identified or based on the generated experimental data, widely used cloud systems are presented that allow achieving the desired effect of load balancing between the clusters themselves (Farhad et al., 2016; Leena et al., 2020; Genys \& Krikštolaitis, 2020; Dunets et al., 2020; Dudukalov et al., 2021). In this regard, to preserve the nation's health, especially in the current global conditions after 2020. One of the determining factors will be the improvement of the agricultural sector of the economy based on the concept of the current system of food consumption for the formation of individual agro-industrial clusters that can take into account not only primary processing, storage, and sale of products, but also the social sphere, which has a corresponding well-established infrastructure.

\section{Methods}

When studying the activities of agricultural producers, the authors have applied statistical analysis methods and used a cluster approach based on the structure of metadata received from Rosstat of Russia. In terms of research in the subsector aspect of agricultural commodity producers for crop production, an indicator of the gross harvest was adopted for all enterprises, farmers, and households from 1990-2018. (see Figure 1).

Figure 1. Dynamics of Changes in The Structure of Agricultural Producers in The Crop Production Subsector,\%

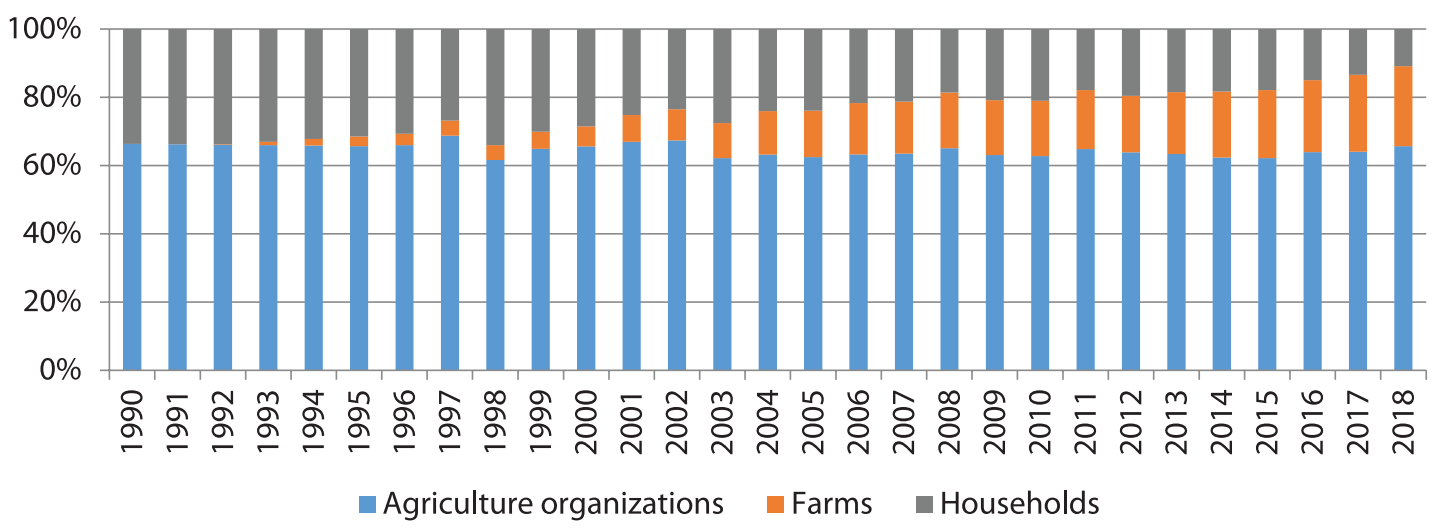


In the process of the identified relationships, built using the method of comparative analysis, we will outline the main factors that are mainly responsible for changes in the structure of gross receipts. In particular, if until 1990, the primary approach to the development of crop production was based on the development of new areas, in the analyzed period, the basis is technological irrigation, the transition to natural conditions, and the expansion of the range of individual farming for the production of an expanded range of products. When analyzing the structure of the gross harvest of crops for the period, it was revealed that the largest share in the gross harvest fell on organizations considered as agricultural producers. Moreover, for the period 2015-2018. the gross collection rate for agricultural producers has increased by $1.8 \%$. The gross harvest from peasants and farms for the same period has not exceeded $0.95 \%$. At the same time, for the period 2017-2018, the largest share in the structure of the studied indicator has been noted for companies engaged in agribusiness, based on the larger cultivated areas.

This aspect was primarily influenced by economic sanctions from the EU member states, considering the expansion of crop production potential concerning individual farmers. At the same time, the risk of returning the available potential land plots to the general turnover may, to a greater extent, affect the pricing policy, an increase in offers, which is not beneficial for large companies with an already established infrastructure. To a greater extent, the nature of the impact of EU sanctions on agricultural producers is a ban on obtaining cheaper borrowed funds from the banking and corporate sectors - obtaining longer-term loan funds at lower interest rates in comparison with the proposed domestic Russian banking structures. As a part of a comprehensive assessment of the structure of the gross harvest, of all the indicators of structural differences, reflecting the rate of change of the entire population for individual groups (Gatev's coefficient, Salai's index, Spearman's correlation coefficient), the authors have chosen the Salai index. At the same time, to differentiate the level of significance of the analyzed factors, the authors used an index adapted to the conditions of the task at hand:

$J_{S}=\sqrt{\sum_{i=1}^{n} \frac{l_{i}}{\sum_{i=1}^{n} l_{i}}\left(\frac{d_{2 i}-d_{1 i}}{d_{2 i}+d_{1 i}}\right)^{2}}$

where $\mathrm{d} 1 \mathrm{i}$ - is the share of the $\mathrm{i}$-th agricultural producer in the reporting period;

$\mathrm{d} 2 \mathrm{i}$ - is the share of the $\mathrm{i}$-th agricultural producer in the base period;

li - is the coefficient of significance. 
Figure 2. Characteristics of Changes in The Structure of Gross Harvest for All Agricultural Producers for The Period 1991-2018, \%

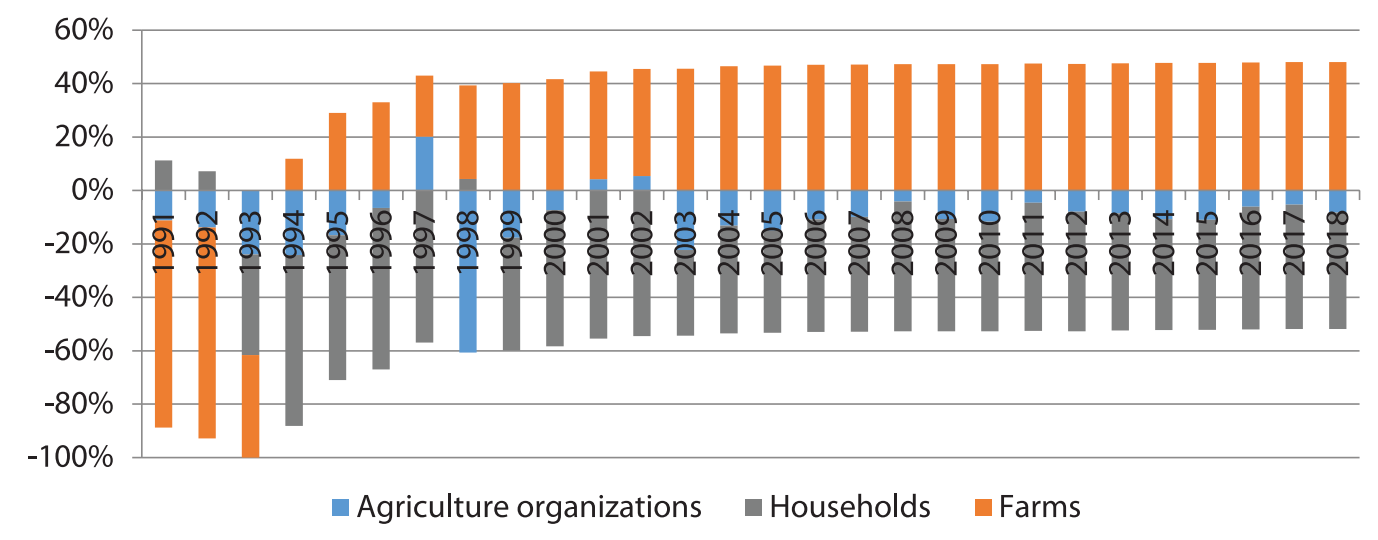

The results of the applied analysis show in Figure 2. It should be noted that the study of the dynamics of indicators in the structure of studies of gross harvest concerning agricultural producers to a greater extent for 1991-2018. showed the dependence of the quality characteristics. Thus, the analysis of statistical indicators showed that the dynamics of the summary indicators of the assessment of structural changes, which correspond to a measurement scale from 0 to 1 (the closer the value of the coefficient is to 1 , the stronger the differences in the structure), are more adaptive and sensitive to the ongoing structural changes. Based on the calculation of the index of structural differences and the rank correlation coefficient in assessing the structural changes in the gross harvest of crops, the authors of the study used the adapted Salai index since it meets the basic requirements for the criteria: standardization, universality and sensitivity, and its interpretation is similar to other coefficients of structural changes. Note that the Salai index distinguishes from others the dependence on the specific share of each group, as a mathematical feature of the fraction formula (the denominator tending to 0 displays the value of the fraction 1 , which leads to conclusions distorting reality). However, the calculations of the index (see Figure 2) showed that none of the shares of the gross collection structure in any period turned to 0 , and therefore the use of the Salai index can be considered legitimate (Moreno et al., 2020).

\section{Results and Discussion}

When studying the nature of agricultural production, it is essential to consider the peculiarities of regional aspects that directly affect the structure of the gross harvest of crops. While analyzing relevant features for the concrete constituencies of the Russian Federation, which to a greater extent serve as the basis for the production of various crops, it has concluded that the most significant share falls on the Central Federal District, 30.0\%, and the smallest - in the Far Eastern Federal District - only 2.0\% (see Figure 3). 
Figure 3. Characteristics of The Volume of Gross Harvest of Agricultural Crops in The Context of Individual Constituent Entities of The Russian Federation,\%.

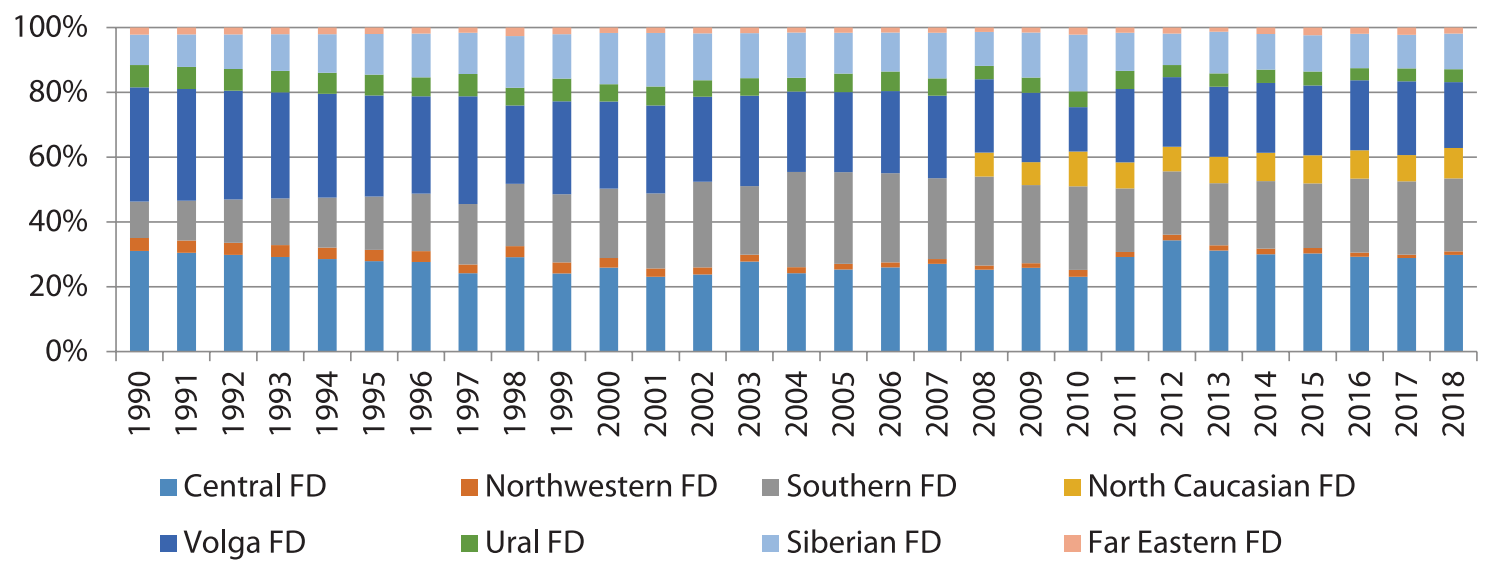

It should be noted that the identified features in the structure of the gross harvest for the corresponding constituent entities of the Russian Federation are determined both by various natural and climatic conditions suitable for growing crops and the value of the corresponding smallest value of their specific value, in particular for the Far Eastern Federal District. On the other hand, for the Central District, which is more significant in terms of relevant indicators, the most influencing factor is the indicator of the development of the financial and banking system compared to other federal districts. In this regard, most producers have opportunities to obtain preferential bank loans for the development and implementation of innovations. At the same time, analyzing the period 2015-2018, it can be noted that crop producers have been facing a choice: on the one hand, there was a prospect of more favorable development for domestic companies due to the introduction of a food embargo for EU countries, and on the other - since recurring macroeconomic problems have affected the agricultural industry as a whole, the lack of investment at the appropriate level did not allow to calculate cost recovery in the form of permanent investments in the industry, and cheap credit money stopped flowing into the Russian economy after 2015. Consequently, in the current situation, the agricultural industry needs support from the public sector, which is more supportive towards larger companies - and farmers and small entrepreneurs can rely only on their resources, particularly on the purchase of seeds and seedlings breeders fertilizers, agricultural machinery. At the same time, if in 1991 the largest share in the structure of the gross harvest of agricultural products was in the Volga Federal District (the share was 35.2\%), and the smallest in the Far Eastern Federal District (2.2\%), then by 2018 the share in Privolzhsky Federal District has decreased by $15 \%$. The reason for this change was a decrease in the level of availability of financial and technological resources for agricultural producers (see Figure 4). 


\section{Figure 4. Characteristics of The Dynamics in The Structure of The Gross Harvest by The Constituent Entities of The Russian Federation,\%}

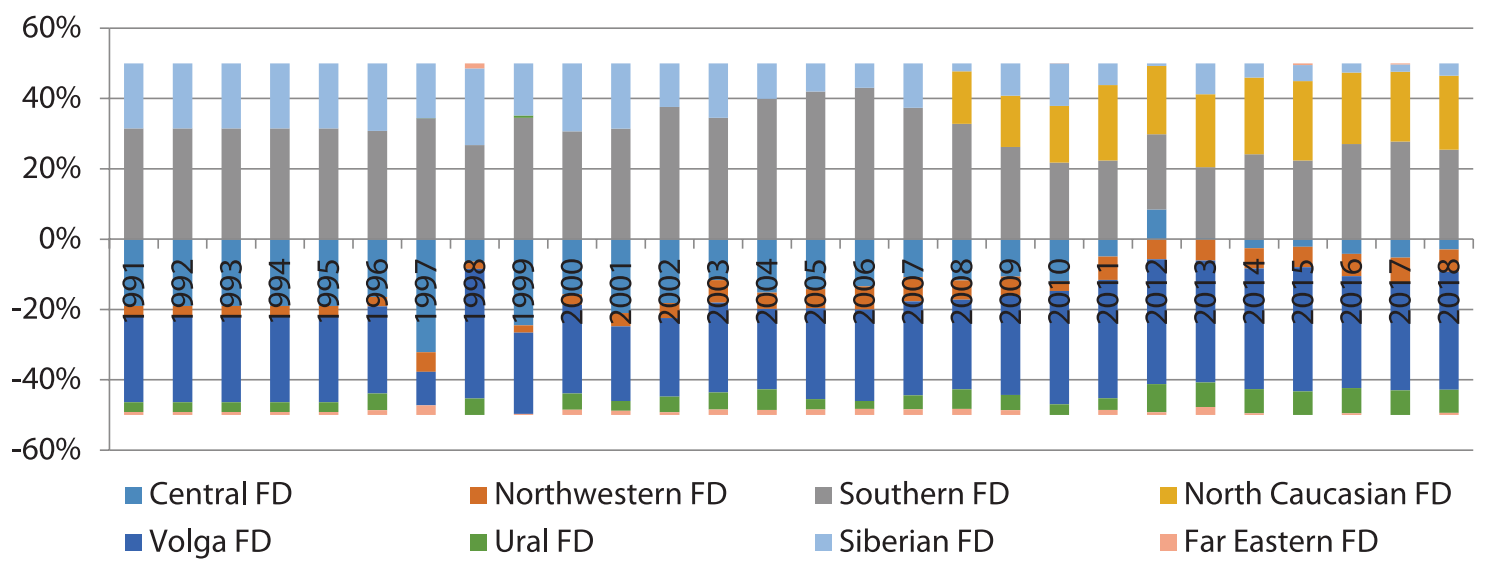

It should be noted that the dynamics of crop production are also influenced by various factors, in particular, the sown area, which is the most significant since it is characterized by the provision of land resources for agricultural producers. At the same time, in 2018, the largest share in the structure of sown areas was in the Volga Federal District (27.49\%), the most minor - in the Northwestern Federal District (1.29\%). In the base year 1991, the largest share in the structure of sown areas has also belonged to the Volga Federal District (30.18\%). This condition is because the chernozem and meadow-chernozem soils of this region are the best for cultivating crops. Therefore, in comparison with 1991, the change in the structure of sown areas was insignificant. When studying the characteristics of the state of agriculture, it is necessary to take into account the indicators of the crop production sub-sector and such indicators as the volume of production of meat, milk, and eggs. These products are classified as strategic due to their high nutritional value. Therefore, it is necessary to identify the federal districts that are the leading suppliers of meat and meat products to the Russian market. The results obtained can be used in the formation and adjustment of the tasks of the state (see Figure 5)

The regional differentiation revealed in the study of the dynamics of dynamics in the structure of sown areas of crops for 1991-2017 allowed the authors to form the following conclusions. Firstly, the most significant volume of production by categories: crop, livestock, and poultry, belongs to the Central Federal District. Secondly, based on the volume of the cultivation area of crops and taking into account the production of milk and eggs and the types of feed consumption, the category of livestock and poultry is correlated to the Volga District. For the analyzed districts, only the Far Eastern district is characterized by the lowest values of agricultural development indicators. In this regard, for the development of agriculture in the medium term, it is necessary to attract sufficient financial capital, primarily for small farms, considering the acceleration of measures on the part of the state. At the same time, for large agricultural enterprises that have consistently changed their export orientation after 2015 to the Asian market, it is necessary to expand the offered range of livestock and poultry products to the Far 
Eastern District. In this regard, the prevailing international competition from South American states may, to a greater extent, affect the general domestic market situation for crops.

Figure 5. Characteristics of Dynamics in The Structure of Sown Areas of Agricultural Crops,\%

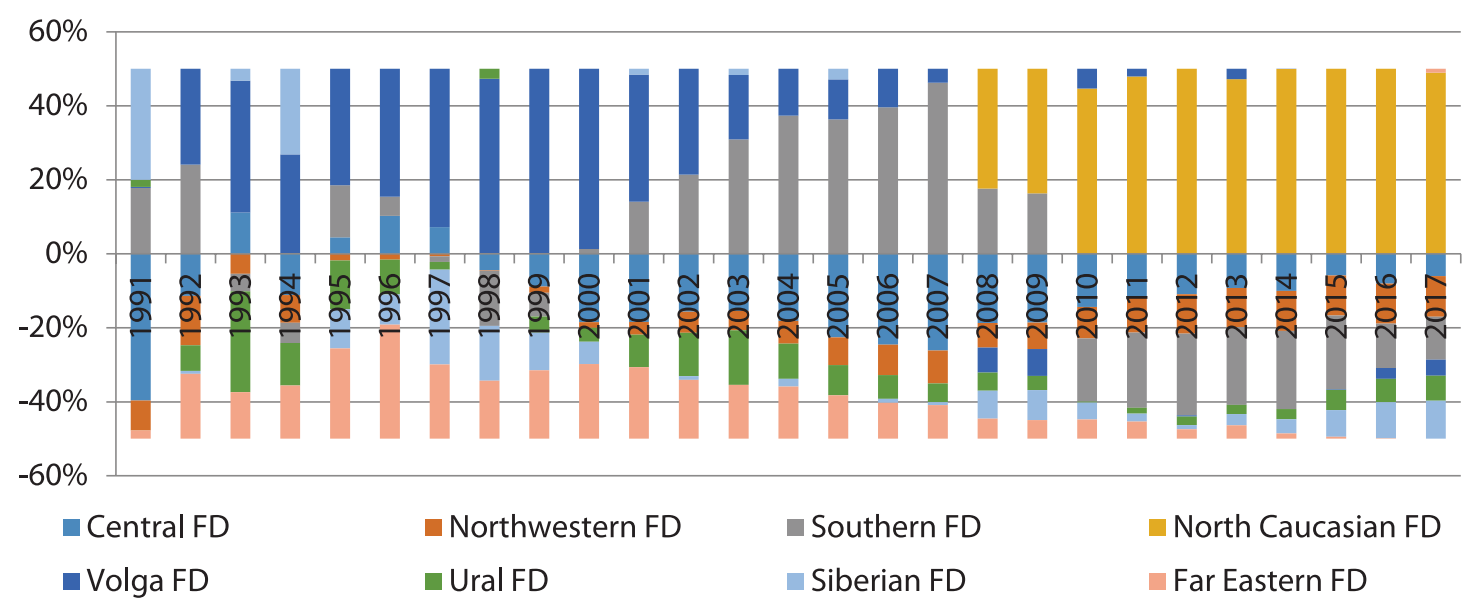

To ensure a high-quality food supply within the urban districts of most states depends on the level of concentration of agricultural and agro-industrial territories. At the same time, the use of anaerobic digestion based on the synthesis of biogas, which belongs to renewable energies, is a valid model associated with treatment to protect fertile soil. When studying the order of formation of the cluster formation of the agro-industrial type, modern researchers tend to use an integrated, hierarchical, and interdisciplinary approach (Silva et al., 2017). We can mostly agree with this since a critical approach in the foreground can contribute to more sustainable development and improve the quality of life (Ho et al., 2020).

At the same time, when conducting cluster analysis in the agro-industrial sector of the economy, it is possible to substantiate the need for further comparison of the results of evaluating standard regression models and taking into account variations within each subgroup for different periods of Taipova (2020). This approach is widely used in practice in agriculture and other spheres of the national economy (Decimo et al., 2017; Aleksandrova \& Agapoya, 2019). However, when building a cluster analysis methodology, not only information technologies and economic and mathematical modeling can be used, but also statistical data sources contained in open sources (Luk'yanova \& Kovshov, 2019; Vasconcelos et al., 2019). In particular, in the practical studies of European economists, the current connection between statistical methods and software products on the example of the Italian agroindustry made it possible to build clusters in agriculture and identify their relationship with industrial territories based on a generalization of the current regional policy (Toccaceli, 2015). Researchers cannot always suggest the extent to which it is necessary to maintain interaction between the state and private partnerships at the level of local self-government in the formation of clusters (Mollard, 2001). For 
example, which factors should be considered when strengthening individual agricultural settlements based on direct budget subsidies (Toccaceli, 2006) or forming clusters to increase competitiveness in the production and marketing of agricultural products (Conti et al., 2019).

It is crucial to ensure the appropriate standards to create centralized water supply, gas supply, or liquefied gas systems for collective use to develop infrastructure support for the cluster of an agricultural settlement (Iacondini et al., 2015; Ostapets, 2019). Streets with at least $80 \%$ hard road surface and a network of road surfaces that provide communication with settlements in the service area. Digital infrastructure facilities provide communication in hard-to-reach areas and warning systems against forest fires (Memarzadeh et al., 2013) and objects of social sphere and housing and communal services and organization of ecological tourism (Kokkinos et al., 2019).

\section{Conclusion}

Direct budget subsidies (usually in the form of special road maps) are mostly used to implement state support for the agro-industrial sector of the economy. In addition to subsidies, the state can implement other support methods in terms of tax incentives and other non-tax measures. As a rule, these methods must be carried out on a systematic basis, taking into account various incentive tools. The methods through the formation of the advanced technologies that have been introduced in states with appropriate industry specialization, taking into account the consumption of financial resources for the development of domestic technologies in the field of the agro-industrial complex and the harmonious agricultural environment through the use of institutions capable of becoming incubators for farmers producing products. In order to reduce the systemic risks inherent in the activities of business entities in the field of agriculture - the agro-industrial cluster, one of the existing ones in practice is the creation of a rural municipal formation of a mixed type (agricultural settlement cluster, ASC). This approach is based on an average settlement in which the majority of the population is engaged in agriculture that considers the corresponding infrastructure's functioning. In terms of its function, the ASC cluster can attribute to the structure of the agro-industrial. This aspect is understandable since it combines digital infrastructure in the production, primary processing, storage, and marketing of agricultural products. As the operating principles of ASC activities, they can be as vertically integrated farming complexes, carried out based on a unified management system, taking into account the peculiarities of the development of social infrastructure, which is capable of ensuring an appropriate quality of life for the population and preserving the ecological component. In turn, in the horizontal plane - small localizations, built on the principle of a single agricultural park capable of timely diversification of its production (vegetable growing and cattle breeding, before crop production and provision of services in the core innovation sphere).

Thus, the formation of a cluster in the form of ASC will allow to a greater extent, to combine into a common established system from production and processing to the 
sale of finished agricultural products both at the local and federal levels. This approach will significantly harmonize the interests of all participants in the agroindustry and significantly simplify and expand access to external export markets, thereby reducing the cost of marketing research and secondary service industries and contractors. At the same time, a cluster in the form of ASC will increase the overall economic impact on individual farmers, which will have a more significant impact on the development of non-raw material zones employed to produce agricultural products. Therefore, it will increase jobs in small townships and contribute to the non-transfer of competent workers to large cities and metropolitan areas.

\section{References}

Ahmed, K., Ahmed, N., Shahbaz, M., Ozturk, I., \& Long, W. (2016). Modelling Trade and Climate Change Policy: a Strategic Framework for Global Environmental Negotiators. Journal of Water and Climate Change, 7(4), 731-748

Aleksandrova, Y.A., \& Agapova, A.A. (2019). Peculiarities of Tax Monitoring in the Russian Federation. Scientific Almanac of Association France-Kazakhstan, 2, 170-174

Antimanon, S., Chamkhuy, W., \& Sutthiwattanakul, S. (2018). Efficient Production of Arachidonic Acid of Mortierella sp. by Solid-state Fermentation Using Combinatorial Medium With Spent Mushroom Substrate. Chemical Papers, 72, 2899-2908.

Bacaria, J., El Aynaoui, K., \& Woertz, E. (2015). Introduction to The Special Section "Food Trade Relations of the Middle East and North Africa with Countries of the Tropics: Opportunities and Risks of South-South Cooperation”. Food Security, 7, 1097-1099.

Baldos, U. L. C., \& Hertel, T. W. (2015). The Role of International Trade in Managing Food Security Risks from Climate Change. Food Security, 7, 275-290.

Bellamy, A. S., Furness, E., Nicol, P., Pitt, H., \& Taherzadeh, A. (2021) Shaping More Resilient and Just Food Systems: Lessons from The COVID-19 Pandemic. Ambio, 50(4), 782-793.

Bouët, A., \& Debucquet, D. L. (2012). Food Crisis and Export Taxation: The Cost of Non-Cooperative Trade Policies. Review of World Economics, 148, 209-233.

Brisbois, M. C., Morris, M., De Lo, R. (2019). Augmenting the IAD Framework to Reveal Power in Collaborative Governance - An Illustrative Application to Resource Industry Dominated Processes. World Development, 120, 159-168

Brunori, G., Branca, G., \& Cembalo, L. (2020). Agricultural and Food Economics: The Challenge of Sustainability. Agricultural Economics, 8, 12-21.

Caselli, M., Fracasso, A., \& Schiavo, S. (2021). Trade Policy and Firm Performance: Introduction to The Special Section. Economics \& Politics, 38, 1-6.

Conti, V., Ruffo, S. S., \& Vitabile, S. (2019). BIAM: a New Bio-inspired Analysis Methodology for Digital Ecosystems Based on a Scale-Free Architecture. Soft Computer, 23, 1133-1150. 
Decimo, M., Quattrini, M., \& Ricci, G. (2017). Evaluation of Microbial Consortia and Chemical Changes in Spontaneous Maize Bran Fermentation. AMB Express, 7, 205-212.

Dudukalov, E., Kuznetsova, I., Poltarykhin, A., Mandrik, N., Aleshko, R., \& Poletaev S. (2021). Modeling Human Capital Dependence and Production with a High Level of Automation. International Review, (1-2), 69-79.

Dunets, A. N., Gerasymchuk, N. A., Kurikov, V. M., Noeva, E. E., Kuznetsova, M. Y., \& Shichiyakh, R. A. (2020). Tourism Management in Border Destinations: Regional Aspects of Sustainable Development of Protected Natural Areas. Entrepreneurship and Sustainability Issues, 7(4), 3253-3268. https://doi.org/10.9770/jesi.2020.7.4(45)

Du, W., \& Li, M. (2020). Assessing The Impact of Environmental Regulation on Pollution Abatement and Collaborative Emissions Reduction: Micro-evidence from Chinese Industrial Enterprises. Environmental Impact Assessment Review, 82, 106382

Farhad, K. K., Mehdi, A. T., Yeganeh, M. J., \& Aliakbar, K. (2016). Calculating The Social Costs of Carbon Dioxide Emissions in Different Provinces of Iran. Journal of Energy Planning and Policy Research, 2(2), 77-110

Genys, D., \& Krikštolaitis, R. (2020). Clusterization of Public Perception of Nuclear Energy in Relation to Changing Political Priorities. Insights into Regional Development, 2(4), 750-764.

Ho, S.H., Zhang, C., Tao, F., Zhang, C., \& Chen, W.H. (2020). Microalgal Torrefaction for Solid Biofuel Production. Trends Biotechnol, 38(9), 1023-1033.

Iacondini, A., Mencherini, U., \& Passarini, F. (2015). Feasibility of Industrial Symbiosis in Italy as an Opportunity for Economic Development: Critical Success Factor Analysis, Impact and Constrains of the Specific Italian Regulations. Waste Biomass Valor, 6, 865-874.

Kokkinos, K., Karayannis, V., \& Lakioti, E. (2019). Exploring Social Determinants of Municipal Solid Waste Management: Survey Processing with Fuzzy Logic and Selforganized Maps Environmental Science and Pollution Research, 26, 35288-35304.

Leena, H. U., Premasudha, B. G., \& Basavaraja, P.K. (2020). Data Optimisation and Partitioning in Private Cloud Using Dynamic Clusters for Agricultural Datasets. International Journal of Dynamics and Control, 8, 1027-1039.

Luk'yanova, M. T., \& Kovshov, V. A. (2019). Modern State and Development Trends in Small Forms of Agribusiness in the Republic of Bashkortostan. Studies on Russian Economic Development, 30, 299-302.

Magdouli, S., Brar, S. K., \& Blais, J. F. (2016). Co-Culture for Lipid Production: Advances and Challenges. Biomass Bioenerg, 92, 20-30.

Memarzadeh, M., Mahjouri, N., \& Kerachian, R. (2013). Evaluating Sampling Locations in River Water Quality Monitoring Networks: Application of Dynamic Factor Analysis and Discrete Entropy Theory. Environmental Earth Sciences, 70, 2577-2585.

Mollard, A. (2001). Qualité et Développement Territorial: Une Grille d'analyse Théorique à Partir de la Rente. Économie rurale, 263, 16-34. 
Moreno, S., Durán, C., \& Galindo, D. (2020). Statistical and Spatial Analysis of Census Data for the Study of Family and Industrial Farming in Colombia. Applied Spatial Analysis and Policy, 13, 693-713.

Ostapets, M. M. (2019). Analysis of Approaches for Investment Project Valuation. Scientific Almanac of the France-Kazakhstan Association, 2, 104-107

Poghosyan, V. (2018). Philosophies of Social Behavior Research: Meta-Analytic Review. Wisdom, 11(2), 85-92. https://doi.org/10.24234/wisdom.v11i2.212.

Silva, S., Rodrigues, A.C., Ferraz, A., Alonso, J. (2017). An Integrated Approach for Efficient Energy Recovery Production from Livestock and Agro-Industrial Wastes. In: Singh L., \& Kalia V. (eds). Waste Biomass Management - A Holistic Approach. Springer, Cham.

Rahman, P. A., \& Shavier, G. D. K. N. F. (2018). Reliability Model of Disk Arrays RAID-5 with Data Striping. IOP Conference Series: Materials Science and Engineering, 327(2). https://doi.org/10.1088/1757-899X/327/2/022087

Taipova, E. (2020). Modeling of Forecast Performance Indicators of Organizations. Journal of the Knowledge Economy, 11, 57-69. https://doi.org/10.1007/s13132-018-0532-2

Toccaceli, D. (2006). Il Distretto Rurale Della Maremma: 1996-2006. Come si Forma un Distretto Rurale in Agriregionieuropa. Anno, 2(6), 54-56.

Toccaceli, D. (2015) Agricultural Districts in the Italian Regions: Looking Toward 2020. Agricultural Economics, 3, 12-21. https://doi.org/10.1186/s40100-014-0019-9

Vasconcelos, B., Teixeira, J. C., Dragone, G., \& Teixeira, J. A. (2019). Oleaginous Yeasts for Sustainable Lipid Production-from Biodiesel to Surf Boards, a Wide Range of "Green" Applications. Applied Microbiology and Biotechnology, 103, 3651-3667.

Warr, P. G. (2001). Welfare Effects of an Export Tax: Thailand's Rice Premium. American Journal of Agricultural Economics, 83(4), 903-920.

Zheng, C.H., Huang, H.L. (2016) Analysis of Technology Diffusion Among Agricultural Industry Clusters by Game Theory. In: Hung J., Yen N., Li KC. (eds) Frontier Computing. Lecture Notes in Electrical Engineering. Springer, Singapore. 